\title{
ESTUDO DA TEMPERABILIDADE DO AÇO SAE 1040*
}

\author{
Amanda Cristina Medeiros da Silva ${ }^{1}$ \\ Luanda Zarria Moraes Jabour ${ }^{1}$ \\ Edileide Alves dos Santos ${ }^{1}$ \\ Lucas Freitas Brasil Marins ${ }^{1}$ \\ José Charles Moraes de Oliveira ${ }^{1}$ \\ Luiz Filipe Macedo Ferreira ${ }^{1}$ \\ Carlos Vinícius de Paes Santos ${ }^{2}$
}

\section{Resumo}

Este trabalho tem o propósito de avaliar a temperabilidade de um aço SAE 1040 através da utilização do ensaio Jominy e posteriormente promover tratamentos térmicos, gerando nos corpos de prova condições de arrefecimento diferenciadas para avaliar a influência da severidade de têmpera da salmoura e óleo. A curva de ensaio Jominy gerada apresentou um comportamento coerente para um aço com médio teor carbono. Já os tratamentos térmicos que foram realizados posteriormente revelaram que o meio que gera o maior acréscimo nas propriedades mecânicas é o resfriamento em salmoura, haja vista que os corpos de prova submetidos a este resfriamento apresentaram o maior de dureza.

Palavras-chave: Tratamento térmico; Têmpera; Ensaio Jominy.

\section{Abstract}

\section{STUDY OF SAE 1040 STEEL HARDENABILITY}

This work aims to evaluate the hardenability of a SAE 1040 steel by using the Jominy test and subsequently promote heat treatments, generating the test bodies, different cooling conditions to evaluate the influence of tempering severity of water, brine and oil. The Jominy test curve generated presented a consistent behavior for a steel with medium carbon content. Have any heat treatments were performed later revealed that the medium that generates the greatest increase in mechanical properties is cooling in brine, given that the samples submitted to this cooling showed the highest hardness.

Keywords: Termictreatements; Tempering; Jominy test.

1 Aluno(a) de graduação em Engenharia de Materiais na Faculdade de Engenharia de Materiais da UNIFFESPA, Marabá, PA, Brasil.

2 Engenheiro de Materiais, Professor na Faculdade de Engenharia de Materiais da UNIFFESPA, Marabá, PA, Brasil. 


\section{INTRODUÇÃO}

As ligas ferrosas possuem grande destaque quanto a utilização em construção mecânica, pois estas, englobam uma serie de propriedades como ductilidade, dureza, resistência e outras. Essas propriedades influenciam diretamente nas aplicações diversificadas dos aços, promovendo um melhor desempenho destes, ou não, o que justifica a preocupação dos engenheiros em conhecê-las e selecioná-las criteriosamente.

Para que se possa empregar um aço de modo coerente deve-se ter uma coleta de dados ampla, pois apenas desta maneira pode-se promover a maior vida útil possível para os componentes [1]. As propriedades mecânicas de um aço dependem intimamente da microestrutura e uma das formas de modificá-la é por intermédio de tratamentos térmicos.

No presente artigo, utilizou-se um aço SAE 1040 para avaliar a temperabilidade mediante a curva obtida no ensaio Jominy. Em seguida propôs-se uma sequência de tratamentos térmicos, nos quais, a única modificação foi a alteração do meio de arrefecimento (salmoura e óleo), para poder avaliar a influência da severidade de têmpera na formação da microestrutural.

\section{MATERIAIS E MÉTODOS}

Os quatro corpos de prova do aço SAE1040 foram cedidos por uma empresa local e entregues na geometria prevista pela norma [2] para a realização do ensaio. Além disso foram utilizados 01 paquímetro, 01 forno mufla da marca JUNG, 01 forno mufla LINN, 01 dispositivo de ensaio Jominy, 01 termopar $\mathrm{Ni} / \mathrm{Cr}$ do tipo K, 01 durometro de bancada da marca PANTEC com indentador de diamante, 01 equipamento de espectrômetro de emissão ótica da marca PANalytical Epsilon 3-XL, 01 microscópio ótico da marca Olympic, 01 lixadeira/politriz, reagente Nital $3 \%$ (3 $\mathrm{mL}$ de $\mathrm{HNO}_{3} \mathrm{em}$ $97 \mathrm{~mL}$ etanol), lixas d'água das granulometrias entre 80 a 1500 e pastas diamantadas com granulometria de 1, 3 e $6 \mu \mathrm{m}$.

A norma NBR 6339/89 [2] prever que os corpos de provas devem ser nas seguintes dimensões: flange $\phi 32,0 \mathrm{~mm}$; espessura do flange 2,5 a $3,0 \mathrm{~mm}$; cilindro $\phi 25,5$ $\mathrm{mm}$; comprimento útil $98,0 \mathrm{~mm}$; comprimento total $101,0 \mathrm{~mm}$. Todas estas dimensões apresentam tolerâncias necessárias para a usinagem dos mesmos. A norma nos remete que decorridoo tempo para a completa austenitização (uma hora), os corpos de prova devem ser resfriados com um jato de água em uma de suas extremidades (no aparato Jominy) durante dez minutos, e em seguida se completou o resfriamento até a temperatura ambiente. Na seqüência retificou-se os planos necessários para a medição de dureza, com profundidades entre 0,5 e 0,9 mm. A Fig.1 apresenta o arrefecimento sofrido pela peça durante o ensaio e a Fig.2 apresenta o esquema utilizado para coletar as durezas. 


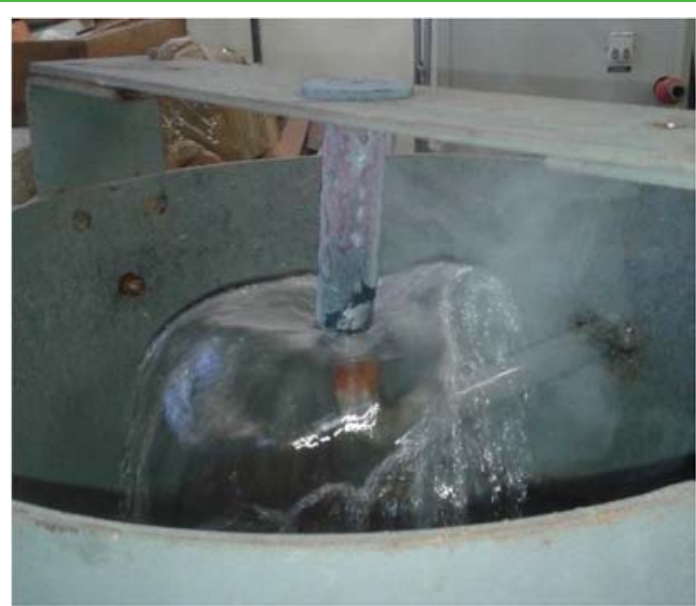

Fig.1. Corpo de prova submetido ao ensaio Jominy.

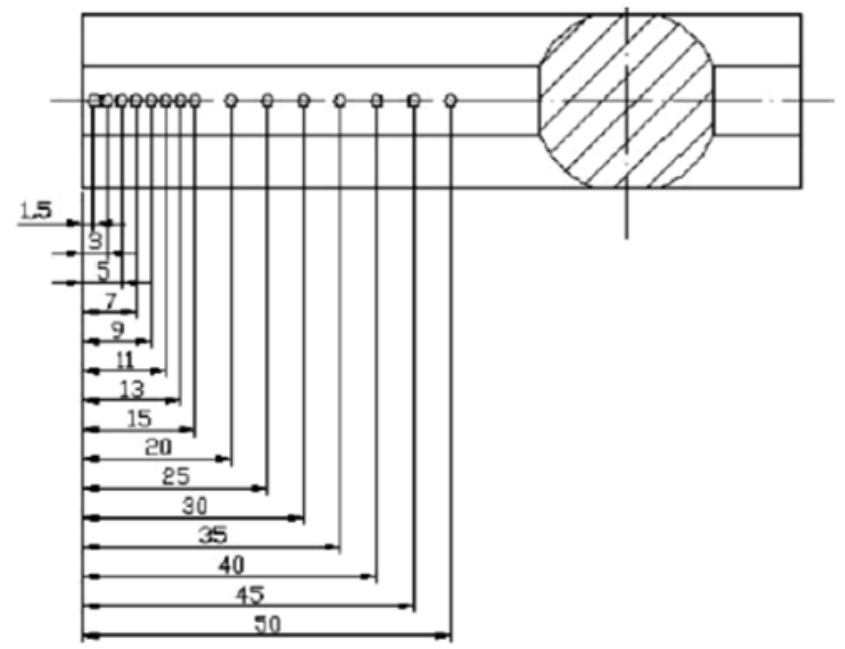

Fig.2. Esquema utilizado para coletar as durezas no corpo de prova [3].

Após a coleta das durezas os corpos de provas foram lixados, polidos e atacados com nital $3 \%$ para passar pela análise metalógrafica através do microscópio ótico, no qual foi possível avaliar as fases obtidas.

Após está averiguação foram selecionados três corpos de prova dentre os analisados para que passarem por normalização a temperatura de $900^{\circ} \mathrm{C}$ por 01 hora e 50 minutos, preparando-os para o tratamento térmico de têmpera a temperatura de $860^{\circ} \mathrm{C}$ por um período de 01 hora e 50 minutos com meios de arrefecimento distintos para cada peça. Os meios selecionados foram água, salmoura e óleo, e posteriormente todas as peças passaram por revenimento a temperatura de $200^{\circ} \mathrm{C}$ por 50 minutos, para verificar a influência das variadas severidades de têmpera impostas pelos meios de resfriamento selecionados.

\section{RESULTADOS E DISCUSSÃO}

A Tab. 01 apresenta a análise da composição química do aço utilizado.

Tabela 1. Composição química do aço AISI 1040

\begin{tabular}{c|c|c|c}
\hline Elemento & $\mathrm{Wt}(\%)$ & Elemento & $\mathrm{Wt}(\%)$ \\
\hline $\mathrm{C}$ & 0,39 & $\mathrm{~S}$ & 0,01 \\
$\mathrm{Si}$ & 0,18 & $\mathrm{Cu}$ & 0,33 \\
$\mathrm{Mn}$ & 0,84 & $\mathrm{Al}$ & 0,02 \\
$\mathrm{P}$ & 0,01 & $\mathrm{Ni}$ & 0,06 \\
\hline
\end{tabular}


O carbono é o elemento primordial para a resistência dos aços comuns, pois durante o processo de tratamento térmico é o principal responsável pelo endurecimento do aço através da transformação martensítica. O fósforo e o enxofre em grandes quantidades conferem fragilidade ao aço, porém o enxofre em particular quando ligado ao manganês melhora a usinabilidade e prejudica a resistência a corrosão, pois deixa a peça mais suscetível a corrosão localizada[4].

O silício é utilizado para atenuar a formação de bolhas nos lingotes, mas não atuam diretamente na resistência mecânica do aço, pois encontram-se em pequenas quantidades, além disso esse elemento é utilizado na siderurgia como um acalmador, em outras palavras, promove a remoção do excesso de gases que são abundantes durante o refino primário do aço e que podem provocar porosidades durante a etapa de solidificação dos lingotes, além disso, promove a inibição da formação de aluminatos que podem promover a obstrução dos tubos utilizados para ecoar o metal liquido durante a solidificação.

O manganês aumenta a forjabilidade, a temperabilidade e a resistência ao impacto, porém tende a ligar-se ao enxofre formando sulfeto que contribui para a fragilização do material. O cobre e o alumínio são inerentes ao processo, podendo causar inclusões[5]. A Fig. 03 mostra a metalografia da amostra como recebido. Pode-se afirmar que há perlita em uma matriz ferrítica e a adição de sulfureto de manganês.

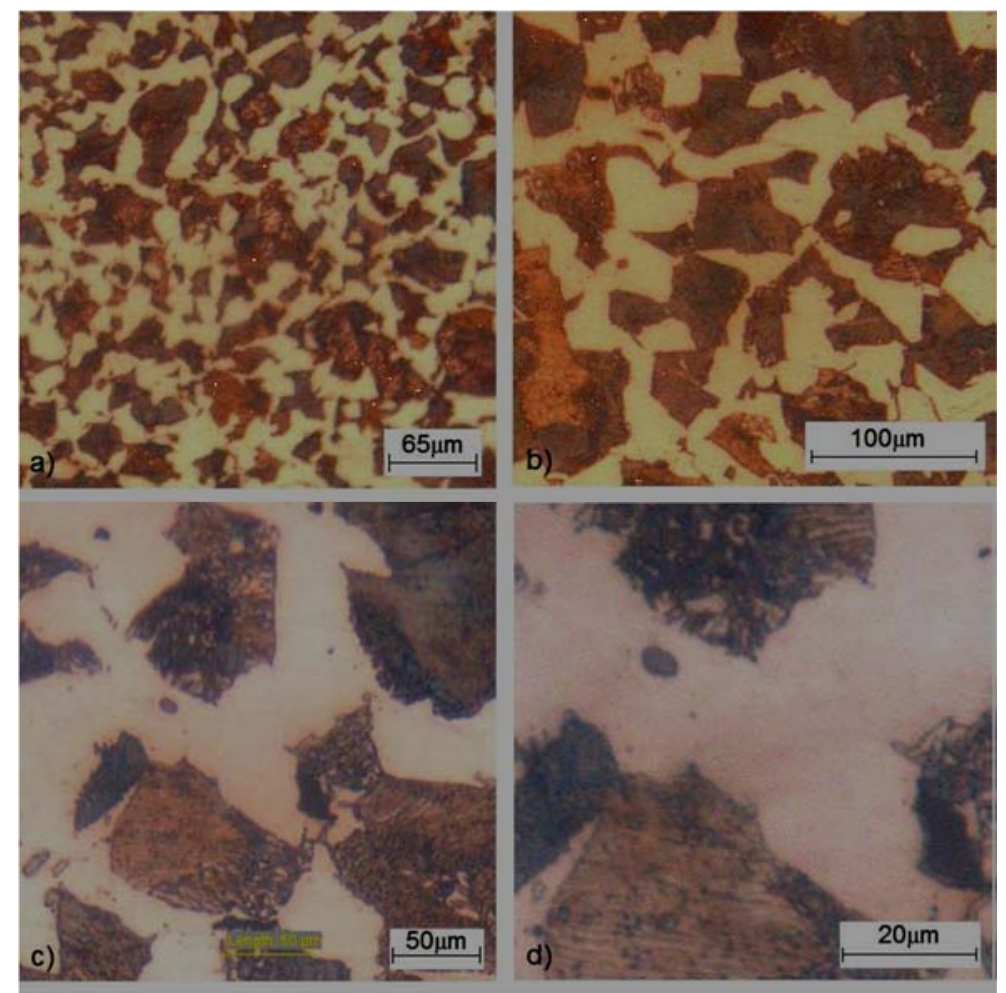

Fig.3. Micrografia do aço SAE 1040 antes da têmpera. Aumento a)150x; b)300x; c)750x; d) 1500x.

A normalização foi feita para refinar e homogeneizar a microestrutura, preparando-a para posterior têmpera e revenido. A Fig. 04 representa a micrografia após a normalização. 


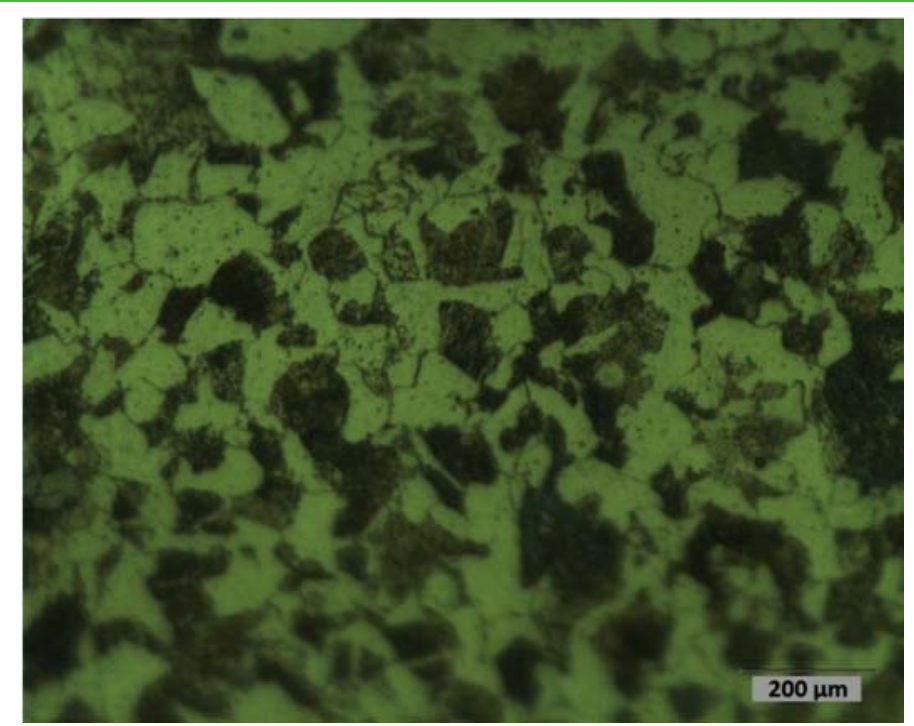

Fig.4. Micrografia do aço SAE 1040 após a Aumento 1500x.normalização.

É possível notar grãos grandes de ferrita, característica de aços médio carbono. A micrografia da têmpera revenido em óleo e em salmoura está representada na Fig. 05.

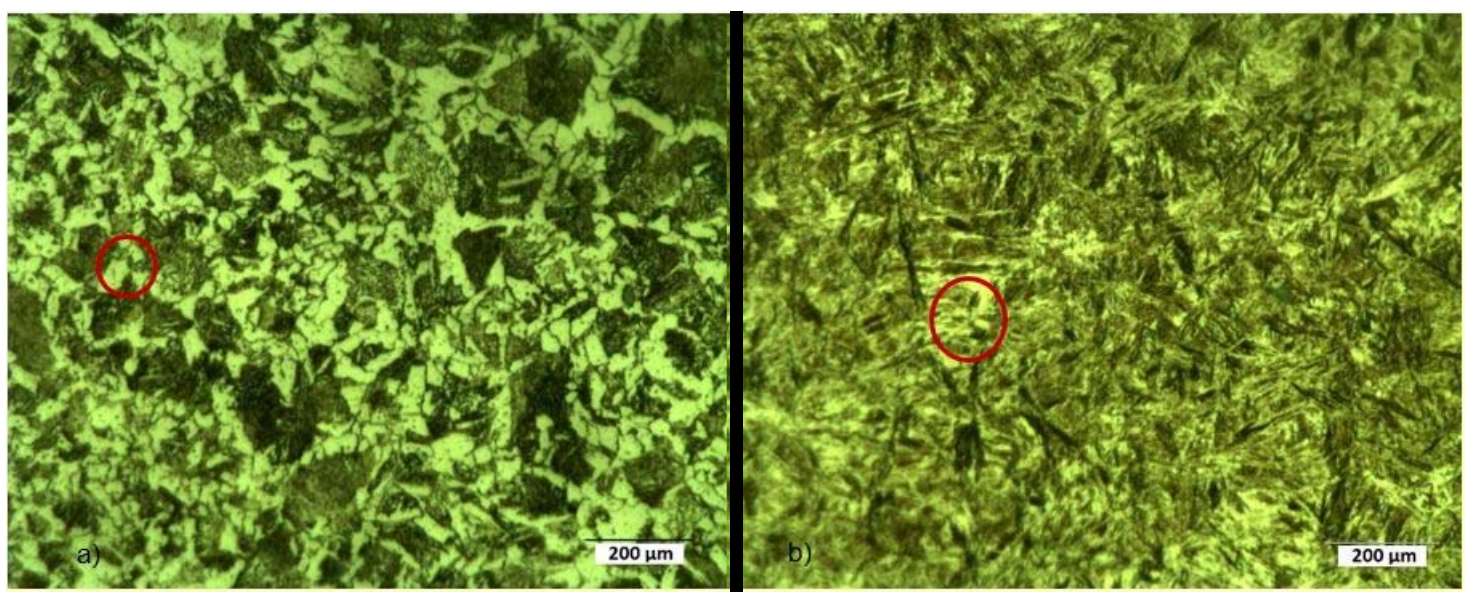

Fig.5. Metalografia do aço SAE 1040 após têmpera e a) revenido em óleo; b) revenido em salmoura. Ambas com 1500x de aumento.

Na Fig. 05 tanto a micrografia temperada em óleo quanto em salmoura apresentam grãos agulhares, como circulado em vermelho, em uma matriz ferrítica, características esperadas para uma microestrutura de um aço médio carbono tratado termicamente[5]. Porém, como a severidade do meio de resfriamento da Fig.05.a) é menor do que a da Fig.05.b) os grãos de ferrita são maiores na primeira estrutura, o que influencia nas propriedades mecânicas, pois conferem mais tenacidade e menor dureza, visto que a presença de grãos agulhares é menor. $\mathrm{O}$ que pode ser comprovado na Tab.02 onde estão os dados de dureza do aço normalizado e logo após o revenido.

Tabela 2. Dureza Rockwell, HRC.

\begin{tabular}{lc}
\hline \multicolumn{1}{c}{ Tratamento Térmico } & Dureza (HRC) \\
\hline Normalização & 9,10 \\
Têm. Em óleo/ revenido & 18,42 \\
Têm. Em salmoura/ revenido & 52,05 \\
\hline
\end{tabular}


A Tab. 02 mostra o aumento da dureza nas peças enfatizando que o tratamento térmico pode ter sido eficiente, haja vista que ocorreu um aumento da dureza das peças de forma qualitativa.

A determinação da curva de ensaio Jominy para o aço SAE 1040 pode avaliar o comportamento dessa liga diante de um tratamento térmico. A curva obtida está presente na Fig. 06.

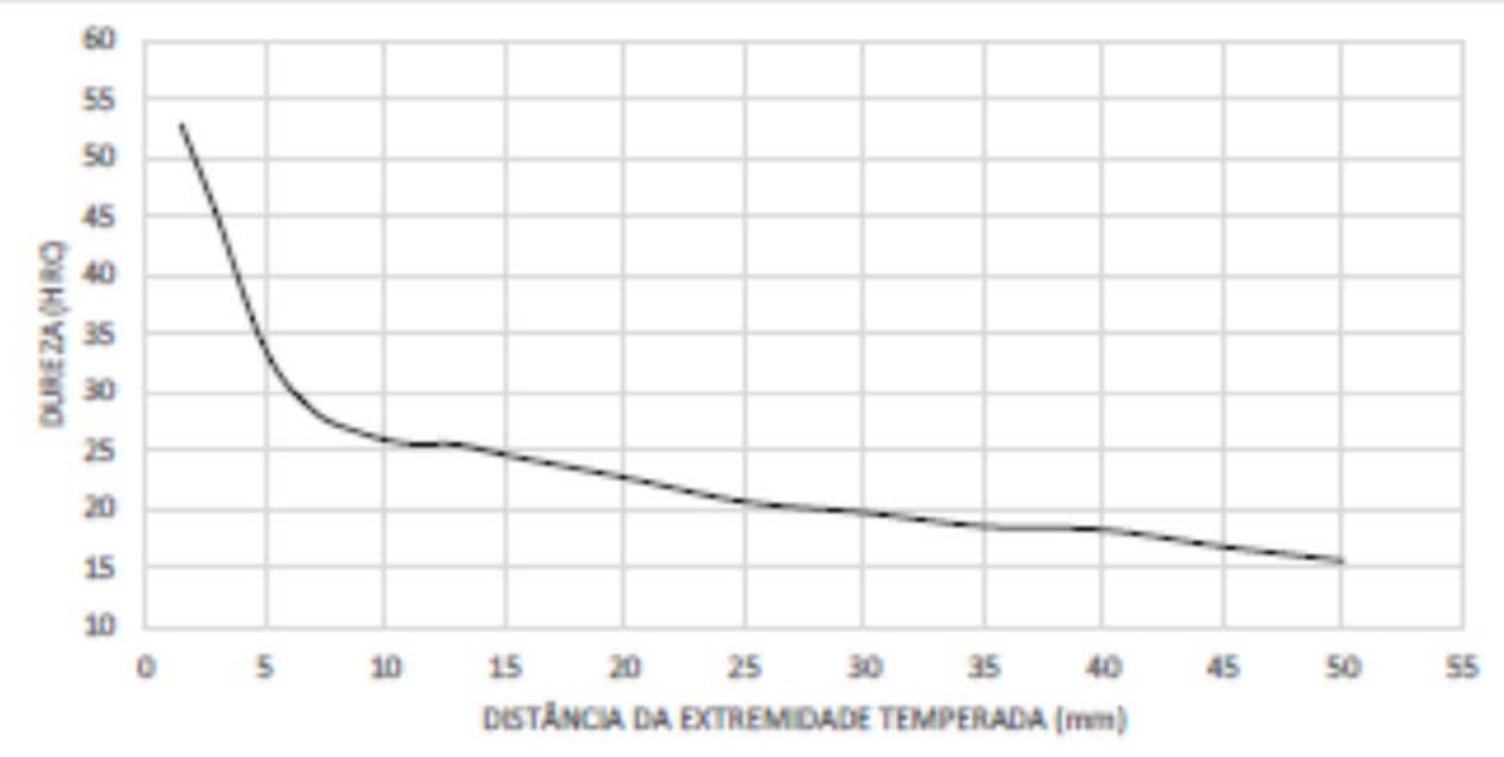

Figura 6. Curva de Temperabilidade do aço SAE 1040

No gráfico da Fig. 06 a dureza da peça diminui com o aumento da distância entre as extremidades do corpo de prova, possuindo uma queda acentuada desta propriedade devido ao modo de resfriamento unidirecional.

A característica apresentada pela curva obtida através do ensaio Jominy pode ser observada em várias outras curvas de temperabilidade como a apresentada na Fig. 07.Nessas curvas se pode notar que os ligados como o ABNT 4340 e o 8640, possuem um desempenho superior no que tange a característica de reter a temperabilidade, haja vista que tais aços possuem elementos de liga. Já para açocarbono só se observa o aumento da temperabilidade, caso ocorra o aumento do teor de carbono do referido aço.

Se formos realizar um comparativo entre o aço 1040 e o seu semelhante da mesma classe 1020 notaremos que o primeiro obteve desempenho superior se comparado ao segundo, haja vista que dispõe de um teor de carbono mais elevado. 


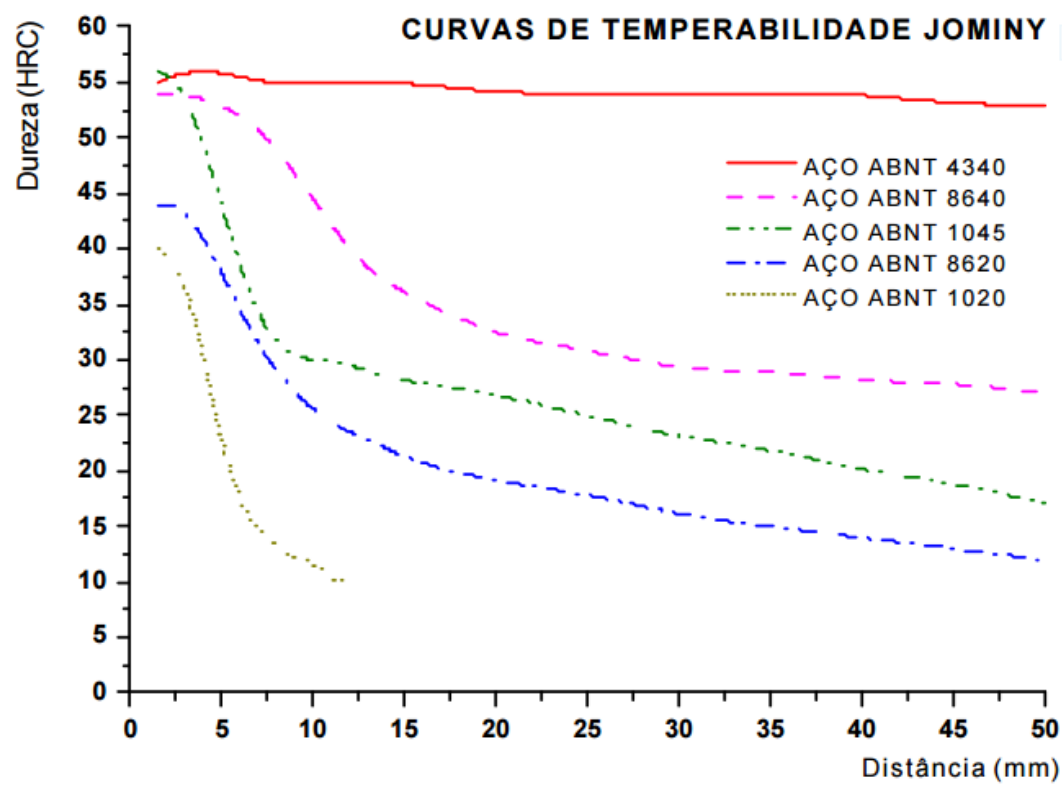

Figura 7. Curva de Temperabilidade do aço SAE 1040 [1].

\section{CONCLUSÃO}

A endurecibilidade está diretamente ligada a composição da liga e a velocidade de resfriamento aplicada. A velocidade de resfriamento de um corpo de prova depende da taxa de extração de calor que é uma característica do meio de resfriamento durante o contato com a superfície do metal, bem como do seu tamanho e sua geometria. A velocidade de resfriamento é conhecida também como "severidade de têmpera".

Dos três meios de têmpera mais comumente empregados (salmoura, água e óleo), a salmoura é a que produz a têmpera mais severa, seguida pela água e óleo[1].

Portanto, o resultado obtido neste trabalho está de acordo com a literatura, visto que a maior dureza foi encontrada na peça arrefecida em salmoura. Isto porque o corpo de prova tem menor tempo para formar qualquer outra microestrutura que necessite de um resfriamento mais lento, não entrando no campo de outras fases que precisam de temperatura para se formarem, como a perlita, por exemplo.

\section{REFERÊNCIAS}

1 MARTINS, M. Temperabilidade jominy e influência do revenido sobre a dureza - um estudo em aços estruturais nacionais, Dissertação de Mestrado UFSC. Florianópolis, 2002.

2 ASSOCIAÇÃO BRASILEIRA DE NORMAS TÉCNICAS - ABNT. Aço, Determinação da Temperabilidade (Jominy). NBR 6339, 1989

3 COLPAERT, H. Metalografia dos Produtos Siderurgicos Comuns. 4ª . ed. São Paulo: Blucher, 2008.

4 SHAMA, P.; ROY, H. Pitting corrosion failure of an AISI stainless steel pointer rod. Engineering Failure Analysis, v. 44, p. 400, 2014.

5 OLUYEMIA, D. O.; OLUWOLEB, O. I.; ADEWUYIB, B. O. Studies of the Properties of Heat Treated Rolled Medium Carbon Steel. Materials Research., v. 14, p. 135-141, 2011. 